\title{
The Nucleus Accumbens and Ventral Pallidum Exhibit Greater Dopaminergic Innervation in Humans Compared to Other Primates
}

\section{Kristen Hirter}

Kent State University

Elaine N. Miller

The George Washington University

Cheryl D. Stimpson

The George Washington University

Kimberley A. Phillips

Trinity University

William D. Hopkins

University of Texas

Patrick R. Hof

Icahn School of Medicine at Mount Sinai

Chet C. Sherwood

The George Washington University

C. Owen Lovejoy

Kent State University

Mary Ann Raghanti ( $\square$ mraghant@kent.edu )

Kent State University https://orcid.org/0000-0002-6842-1907

\section{Research Article}

Keywords: Nucleus accumbens, ventral pallidum, tyrosine hydroxylase, human evolution

Posted Date: March 26th, 2021

DOI: https://doi.org/10.21203/rs.3.rs-344689/v1

License: (c) (i) This work is licensed under a Creative Commons Attribution 4.0 International License.

Read Full License 


\section{Abstract}

Recent evidence suggests that increased dopaminergic signaling within the dorsal striatum played a central role in the evolution of the human brain. This increase has been linked to human pro-sociality and language in what has been described as a dopamine-dominated striatum personality style. Increased striatal dopamine is associated with an increase in ventral striatal activity and promotes externally-driven behaviors, including cooperation and social conformity. In contrast, decreased striatal dopamine is associated with increased dorsal striatal activity andfavors internally driven and goal-oriented behaviors. Previous comparative studies have focused on the dorsal striatum, measuring dopaminergic innervation in the dorsal and medial caudate nucleus and putamen. Here, we add to this knowledge by examining regions of the ventral striatum. We quantified the density of tyrosine hydroxylase-immunoreactive axons, as a measure of dopaminergic innervation, in the nucleus accumbens and ventral pallidum of humans, great apes, platyrrhine and cercopithecid monkeys. Our data show that humans have a significantly greater dopaminergic innervation in both structures, supporting the hypothesis that selection for a prosocial neurochemistry in the human basal ganglia may have contributed to the evolution of our uniquely social behavior profile.

\section{Introduction}

The striatum is a component of the nigrostriatal and mesolimbic dopaminergic pathways that facilitate motor production and reward regulation, respectively (Arias-Carrión et al. 2010; Haber 2003). The nigrostriatal pathway connects the substantia nigra pars compacta with the dorsal striatum (caudate nucleus and putamen) while the mesolimbic pathway connects the ventral tegmental area (VTA) to the ventral striatum, mediating pleasurable experiences (Báez-Mendoza et al. 2013; Haber 2003). The mesolimbic dopaminergic reward pathway is part of the brain's primary mechanism for encoding reward, and has been the subject of numerous clinical studies, as it can be targeted by addictive drugs (Kalivas and Volkow 2005; Volkow and Morales 2015). From an evolutionary standpoint, the reward system can perpetuate behaviors that enhance fitness by linking successful ones to elevated dopamine (DA) (Haber 2003; O'Connell and Hofmann 2011).

The striatum thus plays a major role in modulating social behaviors, particularly those involved in reward. It is therefore of interest that dorsal and ventral regions are functionally distinct (Báez-Mendoza et al. 2013; Báez-Mendoza and Schultz 2013; van den Bos 2015). The dorsal region is involved in internally motivated, goal-directed behavior whereas the ventral region regulates behaviors that are externally guided and is associated with various limbic structures of the brain (van den Bos 2015). Moreover, the ventral striatum is thought to facilitate behavioral flexibility by promoting greater sensitivity to social and environmental cues, thus contributing to cooperation and social conformity in humans (Klucharev et al. 2009; Stallen and Sanfey 2015; van den Bercken and Cools 1982; Zaki et al. 2011). Neurotransmitter concentrations largely regulate differential activity in the striatum with high levels of acetylcholine favoring activity in the dorsal region and its associated internally-motivated behaviors, and increased DA promoting externally guided behaviors that are regulated by the ventral region (Cools et al. 1990; Cools et 
al. 1975; van den Bercken and Cools 1982; van den Bos 2015). These results suggest that individual striatal neurochemical profiles predict individual-specific behaviors and personality style. Inter-individual differences in this system may provide a target for selection by favoring particular behaviors in different environments, and may therefore underlie species-specific social and behavioral adaptations.

Recently, Raghanti et al. (Raghanti et al. 2016; Raghanti et al. 2018) reported that humans, compared to other primates, exhibit a unique striatal neurochemical signature that includes greater DA, serotonin, and neuropeptide $Y$ but decreased acetylcholine in specific regions of the dorsal striatum. The present study builds on these earlier findings by directly quantifying DAergic innervation in the ventral striatum (i.e., nucleus accumbens, NAcc) and ventral pallidum (VP) with the goal of determining if greater DAergic transmission also extends to these regions as well. The NAcc is the ventromedial portion of the ventral striatum with afferent connections with the amygdala and regions of the prefrontal cortex (Haber and McFarland, 1999; Haber et al., 1995; Haber et al., 2006). The VP, located ventral and adjacent to the anterior commissure, receives GABAergic projections from the ventral striatum and projects to additional brain regions that regulate motivation (e.g., Haber and Knutson, 2010). The NAcc and VP are part of the reward system, with the NAcc playing a role in motivational and emotional responses to environmental stimuli and the VP involved in encoding the value of reward as well as the motor actions required to attain reward (e.g., Haber and McFarland, 1999; Tachibana and Hikosaka, 2012). Elevated DA in the NAcc has been linked to social conformity, compassion, and altruism (Filkowski et al. 2016; Klimecki et al. 2014; Klucharev et al. 2009; Stallen and Sanfey 2015). Higher levels of DA in the ventral striatum have also been linked to monogamy in some rodents (Aragona et al. 2006) and increased glucose uptake in both the NAcc and VP has been reported for pair-bonded versus lone male titi monkeys (Bales et al., 2007). Monogamy in these species includes bi-parental care, aggression towards unfamiliar conspecifics, and pair bonding (i.e., partner preference, but not sexual fidelity) (e.g., Young et al., 1998; Young and Wang, 2004).

Humans are among the few species that are characterized by social monogamy, a behavioral pattern hypothesized to have emerged with a reduced canine crown (the "social tooth", indicating reduced aggression) in association with bipedality more than 4 million years ago (Lovejoy 1981; Lovejoy 2009; Lovejoy 2014). We anticipated that monogamous, or semi-monogamous, species within our sample (humans, tamarins, marmosets, and owl monkeys) would possess significantly higher DA within the VP compared to non-monogamous species. We further anticipated that humans would possess higher DA within the NAcc which could account for our uniquely high levels of social conformity and capacity for compassion and altruistic acts.

\section{Materials And Methods}

\section{Specimens}

We processed postmortem brain samples from 50 individuals across nine primate genera. Subjects included platyrrhines (cotton-top tamarins, common marmosets, owl monkeys, and tufted capuchins), 
cercopithecids (pig-tailed and rhesus macaques), African great apes (common chimpanzees and bonobos), and humans (see Table 1 for details). Sexes were balanced as much as possible. All individuals were adult, free of gross neuropathology. Nonhuman primates had been housed in accordance with their home institution's animal care and use standards. We obtained the human brain specimens from the Northwestern University Alzheimer's Disease Center Brain Bank. All individuals were non-geriatric and free of neuropathological disease. We received whole brains or sections for nonhuman primates from the National Chimpanzee Brain Resource, The Great Ape Neuroscience Project, the Oregon National Primate Research Center, the Washington National Primate Research Center, the New England Regional Primate Research Center (Harvard University), Alpha Genesis, and various zoos. Brain samples were fixed by immersion in 10\% buffered formalin for 7-10 days, then transferred to a solution of $0.1 \mathrm{M}$ phosphate-buffered saline (PBS, pH 7.4) containing $0.1 \%$ sodium azide and stored at $4^{\circ} \mathrm{C}$ until further processing.

\section{Sample Processing}

All samples were cryoprotected in a graded series of sucrose solutions $(10 \%, 20 \%$, and $30 \%)$ prior to sectioning. The brain samples were rapidly frozen with dry ice and then sectioned at $40 \mu \mathrm{m}$ using a freezing sliding microtome (SM2000R, Leica, Chicago, IL). Each section was placed into an individual centrifuge tube containing freezer storage solution (30\% each distilled water, ethylene glycol, and glycerol and $10 \% 0.244 \mathrm{M} \mathrm{PBS}$ ), numbered sequentially, and then stored at $-20^{\circ} \mathrm{C}$ until histological or immunohistochemical processing. Every tenth section was Nissl-stained to visualize the regions of interest for immunohistochemical staining and stereological quantification of neuron cell density.

Figures 1 and 2 show the two areas of interest for the present study: the NAcc, which comprises most of the ventral striatum and in this study we conservatively defined as the portion of the ventromedial striatum that is ventral and medial to the inferior border of the internal capsule in sections rostral to the appearance of the anterior commissure ; the VP, which was traced in sections ventral and adjacent to the anterior commissure with readily discernable borders (Paxinos et al. 2000; 2012, Ding et al. 2016; Haber and McFarland, 1999). We did not differentiate between the shell and core region of the NAcc in this study as TH does not provide clear boundaries between these regions (e.g., McCollum et al., 2016).

\section{Immunohistochemistry}

Sections that spanned the NAcc and VP for each subject were stained for tyrosine hydroxylase $(\mathrm{TH})$, the rate-limiting enzyme for catecholamine synthesis, using the avidin-biotin-peroxidase method as described previously (Raghanti et al. 2016; Raghanti et al. 2009; Raghanti et al. 2008). Briefly, sections were pretreated for antigen retrieval by incubating in $0.05 \%$ citraconic acid $(\mathrm{pH} 7.4)$ at $86^{\circ} \mathrm{C}$ in a water bath for 30 minutes. Sections were then rinsed, and endogenous peroxidase was quenched using a solution of $75 \%$ methanol, $2.5 \%$ hydrogen peroxide (30\%), and $22.5 \%$ distilled water for 20 minutes at room temperature. Sections were pre-blocked in a solution of $4 \%$ normal goat serum, $0.6 \%$ Triton X-100 detergent, $90.4 \%$ PBS, and $5 \%$ bovine serum albumin. Following this, sections were incubated in a rabbit anti-TH polyclonal antibody (Millipore, Bedford, MA, AB152, RRID 390204) diluted to 1:1,000 for 24 hours 
at room temperature followed by 24 hours at $4^{\circ} \mathrm{C}$. Sections were then incubated in a biotinylated secondary antibody (1:200) followed by the avidin-peroxidase complex (PK-6100, Vector Laboratories, Burlingame, CA) for 1 hour at room temperature. A 3,3' -diaminobenzidine-peroxidase (DAB) substrate with nickel solution enhancement was used as the chromogen (SK-4100, Vector Laboratories).

\section{Data Acquisition}

Quantitative analyses were performed using computer-assisted stereology on an Olympus BX-51 photomicroscope system equipped with a digital camera and Stereolnvestigator software version 10 (MBF Bioscience, Williston, VT, USA). Subsampling techniques were performed for each species to determine appropriate sampling parameters. TH-immunoreactive (ir) axons were quantified using the SpaceBalls probe at 100x (N.A. 1.4) magnification under Koehler illumination using a hemisphere set at $7 \mu \mathrm{m}$ with a $2 \%$ guard zone. Section thickness was measured at every fifth sampling site with an average mounted section thickness for immunostained sections being $23.9 \pm 8.2 \mu \mathrm{m}$. Sampling grids were optimized for each specimen, with an average grid of 496 x $401 \mu \mathrm{m}$ (range: 106 x 66 - 1632 x 1092). Axons were marked where they intersected the outline of the hemisphere. Axon length density (ALV) was calculated as the total fiber length divided by the planimetric measurement of the reference volume sampled. Based on subsampling results, three sections per region per individual were quantified to reliably provide coefficients of error of less than 0.10 . The section sampling interval ranged from 1 in 5 for smaller brains to 1 in 20 for larger brains. The mean number of sampling sites in the NAcc per individual was $29 \pm 5$ (s.d.) with an average of $131 \pm 38$ axon intersections counted per region. The mean number of sampling sites in the VP per individual was $28 \pm 6$ with an average of $72 \pm 40$ axon intersections counted per region. The Gundersen coefficient of error $(C E, m=1)$ was $0.06 \pm 0.03$.

Neuron density (Nv) and glial density (Gv) were assessed in adjacent Nissl-stained sections using the optical fractionator probe. While neuron densities were quantified for the purpose of standardizing the comparative data, glia densities were also collected at the same time. The ratio of glia to neurons $(\mathrm{G} / \mathrm{N})$ has been used to examine cell type composition across species and brain region (Sherwood et al. 2006). The NAcc and VP were outlined at 4x magnification and neurons and glia were manually counted under a $40 x$ objective (N.A. 0.75) with a counting frame of $50 \times 50 \mu \mathrm{m}$. As there is a significantly large range in the size of the specimens in this comparative sample, sampling grids also varied in size with an average of $550 \times 459 \mu \mathrm{m}$ (range: $78 \times 111$ - $1280 \times 1702$ ). The optical disector height was $7 \mu \mathrm{m}$ with a $2 \%$ guard zone. Section thickness was measured at every 5 th sampling site and the average mounted section thickness for Nissl-stained sections was $13.4 \pm 4.9 \mu \mathrm{m}$. The Gundersen CE ( $m=1)$ was $0.07 \pm 0.003$ for $\mathrm{Nv}$ and $0.06 \pm 0.01$ for $\mathrm{Gv}$. Neurons were identified by the presence of a large, lightly stained nucleus and a distinct nucleolus, accompanied by lightly stained dendritic processes. Glia cells do not possess a visible nucleolus or dendritic processes. Due to the difficulty in differentiating astrocytes, oligodendrocytes, and microglia in Nissl-stained sections, all glia were included. Nv and Gv were calculated as the sum of neurons or glia counted, respectively, within the sum of optical disectors divided by the product and volume of the disector (e.g., Sherwood et al. 2006). 
Because the specimens included in this study are derived from species with vastly different brain sizes, we used the ratio of ALv/Nv for comparative analysis among species. Using neuron density as a denominator provides a variable that accounts for the fact that axons are innervating neurons regardless of brain size. Additionally, glia densities (Gv) and glia-to-neuron ratios were evaluated for each region across species.

\section{Statistical Analysis}

We used IBM SPSS software,TIBCO Statistica Academicand R to analyze the data. Among-species differences were evaluated using analysis of variance (ANOVA) in the NAcc and VP separately. The dependent variables were TH ALv/Nv, Nv, Gv, and glia-to-neuron ratio (G/N). A Brown-Forsythe correction was applied when Levene's test for homogeneity of variance was significant. Significant results were evaluated using Fisher's Least Significant Difference (LSD) post hoc tests. Prior to among-species analyses, separate independent sample T-tests were used to test for differences between sexes in each species. The results from these analyses were non-significant $(p>0.05$ for all), therefore sexes were pooled.

Additional analyses to determine allometric scaling relationships with brain weight were performed using $R$ studio software (R core Team, Vienna, Austria, version 4.0.2). Species mean data were evaluated using phylogenetic generalized least squares (PGLS) to calculate scaling slopes while accounting for the covariance structure of evolutionary relatedness. In these analyses, Aotus spp. individuals were pooled with Aotus trivirgatus. Phylogenetic analysis of covariance (pANCOVA) was used to test whether human values were significantly different from what would be expected for their brain size (Smaers and Rohlf 2016). PGLS and PANCOVA were performed for NAcc and VP data separately. The dependent variables were TH ALv/Nv, Nv, Gv, and glia-to-neuron $(\mathrm{G} / \mathrm{N})$ ratio while the dependent variable was brain weight. The level of significance (a) was set at 0.05 for all statistical tests.

\section{Results}

\section{Among-Species Analyses}

\section{TH ALv/Nv}

Figures 3-6 provide examples of TH immunohistochemical staining of the NAcc and VP for all species. Immunostaining was robust for all individuals used in this study. Tables 2 and 3 provide summary data for all variables by species. ANOVA analysis revealed a significant difference among species for $\mathrm{TH}$ $A L v / N v$ in the NAcc $\left(F_{8,40}=6.25, p<0.025\right.$; Figure 7). Post hoc analyses indicated that humans possess significantly higher TH ALv/Nv in the NAcc relative to all nonhuman primate species ( $p<0.05$ for all). Our next analysis used PGLS to examine allometric scaling of TH ALv/Nv against brain weight while accounting for phylogenetic relatedness in the comparative sample. The PGLS regression indicated a significant positive scaling relationship across the primates between TH ALv/Nv and brain weight for the NAcc $(d f=10$, regression slope $b=0.24,95 \%$ C.I. $=0.13-0.35, p=0.0006$; Figure 8). pANCOVA 
demonstrated that human TH ALv/Nv in the NAcc was significantly higher than expected from the overall primate scaling trend $(d f=3, F=7.73, p=0.021)$.

TH ALv/Nv in the VP was also significantly different among species $\left(F_{8,38}=5.35, p<0.025\right.$; Figure 7), with humans having significantly higher ALv/Nv than nonhuman primate species ( $p<0.05$ for all). PGLS analysis showed that TH ALv/Nv in the VP displayed a signficant positive scaling relationship $(\mathrm{df}=10$, regression slope $b=0.26,95 \%$ C.I. $=0.17-0.36, p=0.0001$; Figure 8). Human TH ALv/Nv in the VP was relatively high, with PANCOVA finding the human value approaching a conventional level for statistical significance in deviating from primate scaling predictions $(\mathrm{df}=3, \mathrm{~F}=3.84, \mathrm{p}=0.082)$.

\section{Neurons and Glia}

NAcc Nv results revealed a significant difference among species $\left(F_{8,40}=4.60, p<0.025\right.$; Figure 7). Post hoc analyses indicated that marmosets possessed significantly higher neuron density than all other species. Humans possessed significantly lower neuron density compared to tamarins, bonobos, and owl monkeys. A significant effect of species was also detected for VP Nv $\left(F_{8,38}=7.98, p<0.025\right.$; Figure 7$)$. Post hoc analyses showed that marmosets have higher neuron densities relative to all species except owl monkeys (all $p$ valuess $<0.05$ ). Owl monkeys have higher densities relative to capuchins and all catarrhines (all p's $<0.05$ ). Tamarins display significantly increased neuron density compared to pigtailed macaques, bonobos, and humans. Capuchins exhibit a significantly lower neuron density than did other platyrrhines. No differences were detected among catarrhines (all p values $>0.05$ ). Interestingly, a species difference was not detected for NAcc Gv $\left(F_{8,40}=1.348, p>0.025\right.$; Figure 7$)$ or VP Gv $\left(F_{8,38}=1.790\right.$, $p>0.025$; Figure 7).

$N A c c G / N$ ratio analyses revealed significant differences among species $\left(F_{8,40}=3.233 p<0.025\right.$; Figure 7). Post hoc analyses indicated that humans displayed a significantly higher $\mathrm{G} / \mathrm{N}$ ratio than all other species except capuchins. Capuchins had a significantly higher $\mathrm{G} / \mathrm{N}$ ratio than all other platyrrhine monkeys. VP G/N analyses were significantly different among species $\left(F_{8,38}=4.28, p<0.025\right.$; Figure 4$)$. Humans possess a significantly higher $\mathrm{G} / \mathrm{N}$ ratio than all other species except pig-tailed macaques and bonobos. Both species display a higher $\mathrm{G} / \mathrm{N}$ ratio compared to all platyrrhines.

PGLS analyses (Figure 9) indicated significant negative scaling between Nv and brain weight in the NAcc $(\mathrm{df}=10$, regression slope $\mathrm{b}=-0.19,95 \% \mathrm{C} . \mathrm{I} .=-0.31--0.07, \mathrm{p}=0.0062)$ and the VP $(\mathrm{df}=10$, regression slope $b=-0.29,95 \%$ C.I. $=-0.42--0.15, p=0.0009)$. In contrast, there was no relationship between Gv and brain weight in the NAcc ( $d f=10$, regression slope of $b=0.02,95 \%$ C.I. $=-0.08-0.13, p=0.6374$ ) or the VP $(d f=10$, regression slope $b=-0.07,95 \%$ C.I. $=-0.16-0.02, p=0.0964)$. The $G / N$ ratios in each region, consequently, displayed positive allometric scaling: NAcc $(\mathrm{df}=10$, regression slope $b=0.40,95 \%$ C.I. $=0.23-0.57, p=0.0003)$ and VP $(d f=10$, regression slope of $b=0.21,95 \%$ C.I. $=0.11-0.32, p=$ 0.001). pANCOVA analysis indicated that humans do not differ from the overall primate trend in neuron and glia densities of NAcc and VP, or for G/N ratio in VP. However, the human G/N ratio in the NAcc did depart significantly from the overall primate trend in being elevated ( $d f=3, F=6.35, p=0.033$ ). 


\section{Discussion}

DA transmission in the ventral striatum plays a major role in behavioral flexibility. The ability to evaluate different levels of reward, especially those involving value versus risk, as well as simultaneously reducing the likelihood of adverse outcomes, are essential components of developing goal-directed behavior, especially in the context of group living (Haber 2014). DA released from the VTA into the NAcc mediates incentive salience, especially the motivation to behave in a particular way in response to certain stimuli (Báez-Mendoza et al. 2013; Báez-Mendoza and Schultz 2013). Although the roles of DAergic pathways in modulating cognition, social behavior, and personality in both human and other primates are yet to be fully explored, these systems likely impact social organization, reproductive strategies, and foraging patterns.

We originally anticipated that humans and other monogamous and semi-monogamous primates would share increased DA within one or both regions of interest based on previous studies conducted in rodent species (Aragona et al. 2006; Curtis et al. 2006). However, owl monkeys, marmosets, and tamarins did not exhibit increased DA relative to non-monogamous species in our study. While this deviates from what we expected from work conducted in prairie voles, it is consistent with what has been reported for titi monkeys (Callicebus cupreus). Hostetler and colleagues (2017) examined DA binding (to the D1 receptor) in male titi monkeys after their pairing with a female and found an increase in the lateral septum, but not in the NAcc or other regions implicated in the prairie vole model of monogamy. While features of the neuroanatomical substrates that regulate monogamy are likely conserved among mammals (Young and Wang 2004), these results highlight the need for further development of nonhuman primate and other models for gaining a more comprehensive understanding of how neurobiology modulates behaviors across species (Phillips et al. 2014; Preuss 2019). In particular, our ability to distinguish whether monogamous marmosets, tamarins, and owl monkeys display a particular DAergic ventral striatum profile would have been improved if we had additional non-monogamous platyrrhine primates besides capuchins for our outgroup comparisons. Further, inclusion of monogamous primate species phyletically closer to humans (e.g., gibbons and siamangs) may provide additional resolution.

We previously argued that a change in neurochemistry, including a more DA-dominated striatum, may have been pivotal in the evolution of the human lineage by supporting an increased sensitivity to social and environmental cues as well as decreased within-group aggression (Raghanti et al., 2018). Such changes may have been coincident with the emergence of bipedality and the reduction of the canine (the social tooth) with loss of the entire sectorial cutting complex $>4$ million years ago (e.g., Holloway, 1967; Lovejoy, 2009). The striatum plays a major role in social behaviors, particularly those involved in social reward (e.g., Baez-Mendoza et al., 2013). Research in nonhuman primates, rodents, and cats has demonstrated that relative activity levels of dorsal versus ventral striatal regions contributes to individual personality style (e.g., exploratory behaviors, sensitivity to social and environmental cues, extraversion, etc.) (see van den Bos, 2015; Van der Bercken and Cools, 1982 for reviews). Individuals with increased relative activity in the dorsal striatum were more internally-motivated with a high degree of autonomy and a more superficial knowledge of their environment, and were more aggressive, dominant, and less 
responsive to social events. Individuals with increased activity in the ventral striatum were less aggressive and more externally driven, with a greater interest in their environment. They were also highly responsive to social stimuli (reviewed in van den Bos, 2015; Van der Bercken and Cools, 1982).

Striatal neurochemistry has been linked to behaviors that are associated with these 'personality styles', including exploratory behaviors, sensitivity to social and environmental cues, extraversion, etc. (e.g., Bergey et al., 2016; Cools et al., 1975; Jolly et al., 2008; Jolly et al., 2013; Higley et al., 1996; Raleigh et al., 1991; Rilling and Sanfey, 2011; Tanaka et al., 2004; Tanaka et al., 2007; Van den Bercken and Cools, 1982). Increased DA shifts activity to the ventral striatum and its associated personality style while decreased DA shifts activity to the dorsal striatum and its associated behaviors. Individual variation in personality styles and their effects on potential cooperative interaction could have been targets of selection in early human ancestral populations. Enhanced awareness of habitat, decreased aggression, and elevated social conformity are all associated with a DA-dominated striatum personality style, and each could have very well improved survivorship and reproductive success, thus ultimately undergoing strong selection (Raghanti et al. 2018).. Moreover, further expansion of this personality style may have provided the cognitive flexibility and social intelligence underlying not only on human acquisition of language and speech, but also a strong tendency towards social conformity, altruism, and empathy - the suite of extraordinary characters that have come to define human uniqueness.

While personality style and social behaviors can be linked to current experimental data from primate and rodent species, it is important to note that these postmortem analyses cannot definitively link specific cognitive or behavioral characteristics with innervation patterns. This level of interpretation will require future research to allow a more complete understanding of the neuroanatomical bases of human versus nonhuman behaviors.

\section{Declarations}

\section{ACKNOWLEDGEMENTS}

This research was funded by the National Science Foundation (NSF BCS-1846201 to M.A.R. and SMA1542848 and EF-2021785 to C.C.S. and W.D.H.). Elaine Miller was supported by the National Science Foundation Graduate Research Fellowship Program (1746914). We would like to thank Dr. Richard S. Meindl for statistical advice. We are grateful to each of the following for the use of brain materials: The National Chimpanzee Brain Resource (NIH grant NS092988), NINDS grants NS-402867 and NS0-73134, The Great Ape Aging Project (supported by NIH grant AG014308), the National Primate Research Center

at the University of Washington (NIH grant RR000166), the Oregon National Primate Research Center (NIH P51 OD011092), the Northwestern University Alzheimer's Disease Center Brain Bank (supported by Alzheimer's Disease Core Center grant AG013854, from the National Institute on Aging to Northwestern University, Chicago, IL). 
Funding: This research was funded by the National Science Foundation (NSF BCS-1846201 to M.A.R. and SMA-1542848 and EF-2021785 to C.C.S and W.D.H). Elaine Miller was supported by the National Science Foundation Graduate Research Fellowship Program (1746914).

\section{Conflicts of interest/Competing interests: None}

Ethics approval: Human postmortem brain samples meet the criteria for IRB Exemption 4 under DHHS regulations 45 CFR 46 (46.101). Because no living subjects are involved in this research, this proposal does not qualify for IACUC oversight. However, when alive, all nonhuman primates were housed at research or zoological institutions and were maintained in accordance with each institution's animal care and use guidelines.

\section{Consent to participate: NA}

\section{Consent for publication: NA}

Availability of data and material: All raw data are available and will be posted in the National Chimpanzee Brain Resource website data repository (https://www.chimpanzeebrain.org/data-repository) and can be requested from the corresponding authors.

\section{Code availability: NA}

Authors' contributions Kristen Hirter and Mary Ann Raghanti contributed to the study conception and design. Material preparation, data collection and analysis were performed by Kristen Hirter, Elaine Miller, Cheryl D. Stimpson, Kimberley A. Phillips, William D. Hopkins, Patrick R. Hof, Chet C. Sherwood, C. Owen Lovejoy, and Mary Ann Raghanti. The first draft of the manuscript was written by Kristen Hirter and Mary Ann Raghanti and all authors commented on previous versions of the manuscript. All authors read and approved the final manuscript.

\section{References}

1. Aragona BJ, Liu Y, Yu YJ, Curtis JT, Detwiler JM, Insel TR, Wang Z (2006) Nucleus accumbens dopamine differentially mediates the formation and maintenance of monogamous pair bonds. Nature Neurosci 9:133-139

2. Arias-Carrión O, Stamelou M, Murillo-Rodriguez E, Menéndez-González M, Pöppel E (2010) Dopaminergic reward system: a short integrative review. Int Arch Med 3:24

3. Báez-Mendoza R, Harris CJ, Schultz W (2013) Activity of striatal neurons reflects social action and own reward. Proc Nat Acad Sci USA 110:16634-16639

4. Báez-Mendoza R, Schultz W (2013) The role of the striatum in social behavior. Front Neurosci 7:233

5. Bales KL, Mason WA, Catana C, Cherry SR, Mendoza SP (2007) Neural correltaes of pair-bonding in a monogamous primate. Brain Res 1184:245-253 
6. Bergey CM, Phillips-Conroy JE, DIsotell TR, Jolly CJ (2016) Dopamine pathway is highly diverged in primate species that differ markedly in social behavior. Proc Natl Acad Sci USA 113:6178-6181

7. Calvey $T$ (2019) Human self-domestication and the extended evolutionary synthesis of addiction: How humans evolved a unique vulnerability. Neuroscience 419:100-107

8. Cools AR, Brachten R, Heeren D, Willemen A, Ellenbroek B (1990) Search after neurobiological profile of individual-specific features of Wistar rats. Brain Res Bull 24:49-69

9. Cools AR, Hendriks G, Korten J (1975) The acetylcholine-dopamine balance in the basal ganglia of rhesus monkeys and its role in dynamic, dystonic, dyskinetic, and epileptoid motor activities. $J$ Neural Transm 36:91-105

10. Curtis JT, Liu Y, Aragona BJ, Wang Z (2006) Dopamine and monogamy. Brain Res 1126:76-90

11. Filkowski MM, Cochran RN, Haas BW (2016) Altruistic behavior: Mapping responses in the brain. Neurosci Neuroecon 5:65-75

12. Haber SN (2003) The primate basal ganglia: parallel and integrative networks. J Chem Neuroanat 26:317-330

13. Haber SN, Kunishio K, Mizobuchi M, Lynd-Balta E (1995) The orbital and medial prefrontal circuit through the primate basal ganglia. J Neurosci 15:4851-4867

14. Haber SN (2014) The place of dopamine in the cortico-basal ganglia circuit. Neuroscience 282:248257

15. Haber SN, McFarland NR (1999) The concept of the ventral striatum in nonhuman primates. Ann NY Acad Sci 877:33-48

16. Haber SN, Kim K-S, Mailly P, Cazavara R (2006) Reward-related cortical inputs define a larger striatal region in primates that interface with associative cortical connections, providing a substrate for incentive-based learning. J Neurosci 26:8368-8376

17. Haug $H$ (1987) Brain sizes, surfaces, and neuronal sizes of the cortex cerebri: a stereological investigation of man and his variability and a comparison with some mammals (primates, whales, marsupials, insectivores, and one elephant). Am J Anat 180:126-142

18. Hawkins A, Olszewski J (1957) Glia/nerve cell index for cortex of the whale. Science 126:76-77

19. Herculano-Houzel S (2014) The glia/neuron ratio: How it varies uniformly across brain structures and species and what it means for brain physiology and evolution. Glia 62:1377-1391

20. Higley JD, King ST Jr, Hasert MF, Champoux M, Suomi SJ, Linnoila M (1996) Stability of interindividual differences in serotonin function and its relationship to severe aggression and competent social behavior in rhesus macaque females. Neuropsychopharmacol 14:67-76

21. Holloway RL (1967) Tools and teeth: Some speculations regarding canine reduction. Am Anthropol 69:63-67

22. Hostetler CM et al (2017) Effects of pair bonding on dopamine D1 receptors in monogamous male titi monkeys (Callicebus cupreus). Am J Primatol 79:e22612 
23. Inoue-Murayama M et al (2002) Variation of variable number of tandem repeat sequences in the 3 'untranslated region of primate dopamine transporter genes that affects reporter gene expression. Neurosci Lett 334:206-210

24. Jolly CJ, Phillips-COnroy JE, Kaplan JR, Mann JJ (2008) Cerebrospinal fluid monoaminergic metabolites in wild Papio anubis and $P$. hamadryas are concordant with taxon-specific behavioral ontogeny. Int J Primatol 29:1549-1566

25. Jolly CJ, Phillips-Conroy JE, Kaplan JR, Mann JJ (2013) Monoamine neurotransmitter metabolites in the cerebrospinal fluid of a group of hybrid baboons (Papio hamadryas and P. anubis). Int J Primatol 34:836-858

26. Kalivas PW, Volkow ND (2005) The neural basis of addition: A pathology of motivation and choice. Am J Psychiatry 162:1403-1413

27. Klimecki OM, Leiberg S, Ricard M, Singer T (2014) Differential pattern of functional brain plasticity after compassion and empathy training. Soc Cogn Affect Neurosci 9:873-879

28. Klucharev V, Hytönen K, Rijpkema M, Smidts A, Fernández G (2009) Reinforcement learning signal predicts social conformity. Neuron 61:140-151

29. Lovejoy CO (1981) The origin of man. Science 211:341-350

30. Lovejoy CO (2009) Reexamining human origins in light of Ardipithecus ramidus. Science 326:74e71-74e78

31. Lovejoy CO (2014) Ardipithecus and early human evolution in light of Twenty-First-Century developmental biology. J Anthropol Res 70:337-363

32. Mavridis I (2015) The role of the nucleus accumbens in psychiaric disorders. Psychiatriki 25:282294

33. McCollum LA, McCullumsmith RE, Roberts RC (2016) Tyrosine hydroxylase localization in the nucleus accumbens in schizophrenia. Brain Sruct Function 221:4451-4458

34. Miller GM, Madras BK (2002) Polymorphisms in the 3'-untranslated region of human and monkey dopamine transporter genes affect reporter gene expression. Mol Psychiatry 7:44-55

35. Nowak RM (1999) Walker's Primates of the World. The Johns Hopkins University Press, Baltimore

36. O'Connell LA, Hofmann HA (2011) The vertebrate mesolimbic reward system and social behavior network: A comparative synthesis. J Comp Neurol 519:3599-3639

37. Phillips KA et al (2014) Why primate models matter. Am J Primatol 76:801-827

38. Preuss TM (2019) Critique of pure marmoset. Brain Behav Evol 93:92-107

39. Raghanti MA et al (2016) Human-specific increase in dopaminergic innervation in a striatal region associated with speech and language: a comparative analysis of the primate basal ganglia. J Comp Neurol 524:2117-2129

40. Raghanti MA et al (2018) A neurochemical hypothesis for the origin of hominids. Proc Natl Acad Sci wwwpnas.org/cgi/doi/10.1073/pnas.1719666115 1719666115, E1719661108-E1719661116 
41. Raghanti MA et al (2009) Species-specific distributions of tyrosine hydroxylase-immunoreactive neurons within the prefrontal cortex of anthropoid primates. Neuroscience 158:1551-1559

42. Raghanti MA, Stimpson CD, Marcinkiewicz JL, Erwin JM, Hof PR, Sherwood CC (2008) Cortical dopaminergic innervation among humans, chimpanzees, and macaque monkeys: A comparative study. Neuroscience 155:203-220

43. Raleigh MJ, McGuire MT, Brammer GL, Pollack DB, Yuwiler A (1991) Serotonergic mechanisms promote dominance acquisition in adult male vervet monkeys. Brain Res 559:181-190

44. Rilling JK, Sanfey AG (2011) The neuroscience of social decision making. Annu Rev Psychol 62:2348

45. Sherwood CC et al (2006) Evolution of increased glia-neuron ratios in the human frontal cortex. Proc Natl Acad Sci USA 103:13606-13611

46. Smaers JB, Rohlf FJ (2016) Testing species' deviation from allometric predictions using the phylogenetic regression. Evolution 70:1145-1149

47. Sousa AMM et al (2017) Molecular and cellular reorganization of neural circuits in the human lineage. Science 358:1027-1032

48. Stallen M, Sanfey AG (2015) The neuroscience of social conformity: implications for fundamental and applied research. Front Neurosci 9:337

49. Tachibana Y, Hikosaka O (2012) The primate central pallidum encodes expected reward value and regulates motor action. Neuron 76:826-837

50. Tanaka SC, Doya K, Okada G, Ueda K, Okamoto Y, Yamawaki S (2004) Prediction of immediate and future rewards differentially recruits cortico-basal ganglia loops. Nature Neurosci 7:887-893

51. Tanaka SC, Schweighofer N, Asahi S, Shishida K, Okamoto Y, Yamawaki S, Doya K (2007) Serotonin differentially regulates short- and long-term prediction of rewards in the ventral and dorsal striatum. PLOS ONE. doi.org/10.1371/journal.pone.0001333

52. van den Bercken J, Cools AR (1982) Evidence for the role of the caudate nucleus in the sequential organization of behavior. Behav Brain Res 4:319-337

53. van den Bos $\mathrm{R}$ (2015) The dorsal and ventral striatum play different roles in the programming of social behaviour: a tribute to Lex Cools. Behav Pharmacol 26:6-17

54. Volkow ND, Morales M (2015) The brain on drugs: From reward to addiction. Cell 162:712-725

55. Young LJ, Wang Z, Insel TR (1998) Neuroendocrine bases of monogamy. Trends Neurosci 2:71-75

56. Young LJ, Wang Z (2004) The neurobiology of pair bonding. Nat Neurosci 7:1048-1054

57. Zaki J, Schirmer J, Mitchell JP (2011) Social influence modulates the neural computation of value. Psychol Sci 22:894-900

\section{Tables}

Table 1. Subjects included in analyses. Postmortem interval (PMI) is provided for humans. Specific PMI for nonhuman specimens was not available, but $<24$ hours. Average age for sexual maturity and lifespan 
are provided for nonhuman primates (Nowak, 1999; AnAge Database, https://genomics.senescence.info/species/index.html). 


\begin{tabular}{|c|c|c|c|c|c|c|}
\hline Species & Common name & Sex & $\begin{array}{l}\text { Age } \\
(\mathrm{yr})\end{array}$ & PMI & $\begin{array}{l}\text { Sexual } \\
\text { maturity }\end{array}$ & $\begin{array}{l}\text { Longevity } \\
\text { (yr) }\end{array}$ \\
\hline Callithrix jacchus & Common marmoset & M & 4.5 & - & $11-24$ months & 22.8 \\
\hline Callithrix jacchus & Common marmoset & M & 2.75 & - & 11-24 months & 22.8 \\
\hline Callithrix jacchus & Common marmoset & M & 6 & - & 11-24 months & 22.8 \\
\hline Callithrix geoffroyi & $\begin{array}{l}\text { Geoffroy's } \\
\text { marmoset }\end{array}$ & $M$ & 5.7 & - & 11-24 months & 17.6 \\
\hline $\begin{array}{l}\text { Callithrix } \\
\text { geoffroyi^ }\end{array}$ & $\begin{array}{l}\text { Geoffroy's } \\
\text { marmoset }\end{array}$ & M & 8.5 & - & $11-24$ months & 17.6 \\
\hline $\begin{array}{l}\text { Callithrix } \\
\text { pygmaeus }\end{array}$ & Pygmy marmoset & $\mathrm{F}$ & 11.25 & - & 18-24 months & 18.6 \\
\hline Saguinus oedipus & Cotton-top tamarin & $M$ & 10.9 & - & 18-24 months & 26.2 \\
\hline Saguinus oedipus & Cotton-top tamarin & $M$ & 8.4 & - & 18-24 months & 26.2 \\
\hline Saguinus oedipus & Cotton-top tamarin & $M$ & 9.5 & - & 18-24 months & 26.2 \\
\hline Saguinus oedipus & Cotton-top tamarin & $\mathrm{F}$ & 10 & - & 18-24 months & 26.2 \\
\hline Saguinus oedipus & Cotton-top tamarin & $\mathrm{F}$ & 10 & - & 18-24 months & 26.2 \\
\hline Saguinus oedipus & Cotton-top tamarin & $\mathrm{F}$ & 10 & - & 18-24 months & 26.2 \\
\hline Aotus trivirgatus* & $\begin{array}{l}\text { Northern owl } \\
\text { monkey }\end{array}$ & $M$ & $>18$ & - & 2 years & 30.1 \\
\hline Aotus spp. & Owl monkey & M & 18 & - & 2 years & 27 \\
\hline Aotus spp. & Owl monkey & $\mathrm{F}$ & 3 & - & 2 years & 27 \\
\hline Aotus vociferans & Spix's night monkey & $\mathrm{F}$ & 5 & - & 2 years & 22.1 \\
\hline Cebus apella & Tufted capuchin & M & 2.9 & - & $4-8$ years & 46 \\
\hline Cebus apella & Tufted capuchin & M & 16.6 & - & 4-8 years & 46 \\
\hline Cebus apella & Tufted capuchin & M & 15.9 & - & 4-8 years & 46 \\
\hline Cebus apella & Tufted capuchin & $\mathrm{F}$ & 12.6 & - & $4-8$ years & 46 \\
\hline Cebus apella & Tufted capuchin & $\mathrm{F}$ & 17.5 & - & $4-8$ years & 46 \\
\hline Cebus apella & Tufted capuchin & $\mathrm{F}$ & 18.3 & - & $4-8$ years & 46 \\
\hline Macaca mulatta & Rhesus macaque & M & 8 & - & 2.5-8 years & 40 \\
\hline Macaca mulatta & Rhesus macaque & M & 13 & - & 2.5-8 years & 40 \\
\hline Macaca mulatta & Rhesus macaque & $M$ & 13 & - & 2.5-8 years & 40 \\
\hline Macaca mulatta & Rhesus macaque & $\mathrm{F}$ & 14 & - & $2.5-8$ years & 40 \\
\hline
\end{tabular}




\begin{tabular}{|c|c|c|c|c|c|c|}
\hline Macaca mulatta & Rhesus macaque & $\mathrm{F}$ & 11 & - & $2.5-8$ years & 40 \\
\hline Macaca mulatta & Rhesus macaque & $\mathrm{F}$ & 12.5 & - & $2.5-8$ years & 40 \\
\hline $\begin{array}{l}\text { Macaca } \\
\text { nemestrina }\end{array}$ & Pigtailed macaque & M & 15.73 & - & $2.5-8$ years & 37.6 \\
\hline $\begin{array}{l}\text { Macaca } \\
\text { nemestrina }\end{array}$ & Pigtailed macaque & M & 4.28 & - & $2.5-8$ years & 37.6 \\
\hline $\begin{array}{l}\text { Macaca } \\
\text { nemestrina }\end{array}$ & Pigtailed macaque & $M$ & 2.5 & - & $2.5-8$ years & 37.6 \\
\hline $\begin{array}{l}\text { Macaca } \\
\text { nemestrina }\end{array}$ & Pigtailed macaque & $\mathrm{F}$ & 15.1 & - & $2.5-8$ years & 37.6 \\
\hline $\begin{array}{l}\text { Macaca } \\
\text { nemestrina }\end{array}$ & Pigtailed macaque & $\mathrm{F}$ & 14 & - & $2.5-8$ years & 37.6 \\
\hline $\begin{array}{l}\text { Macaca } \\
\text { nemestrina }\end{array}$ & Pigtailed macaque & $\mathrm{F}$ & 5.95 & - & $2.5-8$ years & 37.6 \\
\hline Pan troglodytes & Chimpanzee & $M$ & 19.8 & - & $7-9$ years & 59.4 \\
\hline Pan troglodytes & Chimpanzee & $M$ & 19.5 & - & $7-9$ years & 59.4 \\
\hline Pan troglodytes & Chimpanzee & $\mathrm{F}$ & 30.8 & - & $7-9$ years & 59.4 \\
\hline Pan troglodytes & Chimpanzee & $\mathrm{F}$ & 18.5 & - & $7-9$ years & 59.4 \\
\hline Pan troglodytes* & Chimpanzee & $\mathrm{F}$ & 17.8 & - & $7-9$ years & 59.4 \\
\hline Pan paniscus & Bonobo & M & 34 & - & $7-9$ years & 55 \\
\hline Pan paniscus & Bonobo & M & 5 & - & $7-9$ years & 55 \\
\hline Pan paniscus & Bonobo & M & 25 & - & 7-9 years & 55 \\
\hline Pan paniscus & Bonobo & $\mathrm{F}$ & 52 & - & 7-9 years & 55 \\
\hline Pan paniscus* & Bonobo & $\mathrm{F}$ & 25 & - & $7-9$ years & 55 \\
\hline Homo sapiens & Human & M & 44 & 19 & & \\
\hline Homo sapiens & Human & M & 56 & 15 & & \\
\hline Homo sapiens & Human & M & 44 & 24 & & \\
\hline Homo sapiens & Human & $\mathrm{F}$ & 39 & 19 & & \\
\hline Homo sapiens & Human & $\mathrm{F}$ & 25 & 12 & & \\
\hline Homo sapiens & Human & $\mathrm{F}$ & 53 & 17 & & \\
\hline
\end{tabular}

*, only included in among-species analysis for NAcc; ${ }^{\wedge}$, only included in among-species analysis for VP. 
Table 2. Summary data for TH axon length density (ALv), neuron density (Nv), TH ALv/Nv, glia density $(G v)$, and glia to neuron ratio (G/N) for each species in the nucleus accumbens (NAcc).

\begin{tabular}{|c|c|c|c|c|c|c|}
\hline Genus & $\begin{array}{l}\text { TH ALv } \\
\left(\mu \mathrm{m} / \mu \mathrm{m}^{3}\right)\end{array}$ & & $\mathrm{Nv}\left(\mu \mathrm{m}^{3}\right)$ & TH ALv/Nv & $\mathrm{Gv}\left(\mu \mathrm{m}^{3}\right)$ & $G / N$ \\
\hline Callithrix spp. & $\begin{array}{l}35,359,503 \\
13,126,716\end{array}$ & \pm & $\begin{array}{l}159,788 \pm \\
81,939\end{array}$ & $\begin{array}{l}241.29 \pm \\
90.13\end{array}$ & $\begin{array}{l}133,260 \pm \\
73,634\end{array}$ & $.85 \pm .15$ \\
\hline $\begin{array}{l}\text { Saguinus } \\
\text { oedipus }\end{array}$ & $\begin{array}{l}20,456,808 \\
6,463,875\end{array}$ & \pm & $\begin{array}{l}94,391 \pm \\
25,711\end{array}$ & $\begin{array}{l}229.34 \pm \\
99.55\end{array}$ & $\begin{array}{l}88,419 \pm \\
20,584\end{array}$ & $\begin{array}{l}1.02 \pm \\
.43\end{array}$ \\
\hline Aotus spp. & $\begin{array}{l}30,569,387 \\
7,253,895\end{array}$ & \pm & $\begin{array}{l}101,139 \\
\pm 51,251\end{array}$ & $\begin{array}{l}337.91 \pm \\
109.9\end{array}$ & $\begin{array}{l}84,868 \pm \\
48,672\end{array}$ & $.81 \pm .10$ \\
\hline Cebus apella & $\begin{array}{l}29,610.015 \\
15,075,605\end{array}$ & \pm & $\begin{array}{l}61,559 \pm \\
44,520\end{array}$ & $\begin{array}{l}467.69 \pm \\
167.4\end{array}$ & $\begin{array}{l}137,895 \pm \\
41,112\end{array}$ & $\begin{array}{l}3.00 \pm \\
1.76\end{array}$ \\
\hline $\begin{array}{l}\text { Macaca } \\
\text { mulatta }\end{array}$ & $\begin{array}{l}17,766,455 \\
7,115,746\end{array}$ & \pm & $\begin{array}{l}67,524 \pm \\
22,498\end{array}$ & $\begin{array}{l}256.58 \pm \\
84.69\end{array}$ & $\begin{array}{l}110,359 \pm \\
35,704\end{array}$ & $\begin{array}{l}2.01 \pm \\
1.44\end{array}$ \\
\hline $\begin{array}{l}\text { Macaca } \\
\text { nemestrina }\end{array}$ & $\begin{array}{l}17,355,095 \\
7,203,398\end{array}$ & \pm & $\begin{array}{l}51,287 \pm \\
20,536\end{array}$ & $\begin{array}{l}363.78 \pm \\
172.9\end{array}$ & $\begin{array}{l}82,575 \pm \\
15,091\end{array}$ & $\begin{array}{l}1.74 \pm \\
.51\end{array}$ \\
\hline $\begin{array}{l}\text { Pan } \\
\text { troglodytes }\end{array}$ & $\begin{array}{l}26,979,932 \\
2,958,398\end{array}$ & \pm & $\begin{array}{l}77,714 \pm \\
14,057\end{array}$ & $\begin{array}{l}352.70 \pm \\
47.35\end{array}$ & $\begin{array}{l}96,138 \pm \\
52,820\end{array}$ & $\begin{array}{l}1.24 \pm \\
.62\end{array}$ \\
\hline Pan paniscus & $\begin{array}{l}47,311,086 \\
13,961,461\end{array}$ & \pm & $\begin{array}{l}94,127 \pm \\
30,620\end{array}$ & $\begin{array}{l}526.67 \pm \\
135.1\end{array}$ & $\begin{array}{l}120,157 \pm \\
55,220\end{array}$ & $\begin{array}{l}1.30 \pm \\
.40\end{array}$ \\
\hline Homo sapiens & $\begin{array}{l}38,852,153 \\
10,445,364\end{array}$ & \pm & $\begin{array}{l}38,804 \pm \\
17,699\end{array}$ & $\begin{array}{l}1242.2 \pm \\
801.5\end{array}$ & $\begin{array}{l}133,250 \pm \\
47,120\end{array}$ & $\begin{array}{l}4.43 \pm \\
3.73\end{array}$ \\
\hline
\end{tabular}

Table 3. Summary data for TH axon length density (ALv), neuron density (Nv), TH ALv/Nv, glia density $(G v)$, and glia to neuron ratio (G/N) for each species in the ventral pallidum (VP). 


\begin{tabular}{|c|c|c|c|c|c|c|}
\hline Genus & $\begin{array}{l}\text { TH ALv } \\
\left(\mu \mathrm{m} / \mu \mathrm{m}^{3}\right)\end{array}$ & & $\mathrm{Nv}\left(\mu \mathrm{m}^{3}\right)$ & TH ALv/Nv & $G v\left(\mu m^{3}\right)$ & $\mathbf{G} / \mathbf{N}$ \\
\hline Callithrix spp. & $\begin{array}{l}38,424,091 \\
35,379,311\end{array}$ & \pm & $\begin{array}{l}82,282 \pm \\
43,706\end{array}$ & $\begin{array}{l}502.97 \pm \\
545.66\end{array}$ & $\begin{array}{l}207,626 \pm \\
91,768\end{array}$ & $\begin{array}{l}2.49 \pm \\
.27\end{array}$ \\
\hline $\begin{array}{l}\text { Saguinus } \\
\text { oedipus }\end{array}$ & $\begin{array}{l}19,557,066 \\
4,767,129\end{array}$ & \pm & $\begin{array}{l}51,120 \pm \\
8,495\end{array}$ & $\begin{array}{l}391.60 \pm \\
112.07\end{array}$ & $\begin{array}{l}162,862 \pm \\
41,059\end{array}$ & $\begin{array}{l}3.23 \pm \\
.83\end{array}$ \\
\hline Aotus spp. & $\begin{array}{l}25,716,375 \\
8,383,588\end{array}$ & \pm & $\begin{array}{l}69,253 \pm \\
25,266\end{array}$ & $\begin{array}{l}374.53 \pm \\
17.37\end{array}$ & $\begin{array}{l}150,104 \pm \\
78,724\end{array}$ & $\begin{array}{l}2.08 \pm \\
.66\end{array}$ \\
\hline Cebus apella & $\begin{array}{l}19,984,428 \\
8,288,468\end{array}$ & \pm & $\begin{array}{l}33,029 \pm \\
9,107\end{array}$ & $\begin{array}{l}598.78 \pm \\
169.3\end{array}$ & $\begin{array}{l}141,935 \pm \\
35,705\end{array}$ & $\begin{array}{l}4.39 \pm \\
.84\end{array}$ \\
\hline $\begin{array}{l}\text { Macaca } \\
\text { mulatta }\end{array}$ & $\begin{array}{l}14,832,980 \\
4,566,302\end{array}$ & \pm & $\begin{array}{l}31,472 \pm \\
4,827\end{array}$ & $\begin{array}{l}468.96 \pm \\
103.66\end{array}$ & $\begin{array}{l}167,385 \pm \\
47,208\end{array}$ & $\begin{array}{l}5.25 \pm \\
.83\end{array}$ \\
\hline $\begin{array}{l}\text { Macaca } \\
\text { nemestrina }\end{array}$ & $\begin{array}{l}11,345,480 \\
2,104,688\end{array}$ & \pm & $\begin{array}{l}15,333 \pm \\
4,712\end{array}$ & $\begin{array}{l}783.93 \pm \\
215.62\end{array}$ & $\begin{array}{l}101,138 \pm \\
20,833\end{array}$ & $\begin{array}{l}6.87 \pm \\
1.52\end{array}$ \\
\hline $\begin{array}{l}\text { Pan } \\
\text { troglodytes }\end{array}$ & $\begin{array}{l}12,877,586 \\
1,564,131\end{array}$ & \pm & $\begin{array}{l}32,984 \pm \\
22,449\end{array}$ & $\begin{array}{l}515.25 \pm \\
252.51\end{array}$ & $\begin{array}{l}118,253 \pm \\
34,197\end{array}$ & $\begin{array}{l}5.21 \pm \\
4.20\end{array}$ \\
\hline Pan paniscus & $\begin{array}{l}11,379,280 \\
3,935,412\end{array}$ & \pm & $\begin{array}{l}19,540 \pm \\
7,938\end{array}$ & $\begin{array}{l}615.71 \pm \\
171.88\end{array}$ & $\begin{array}{l}139,552 \pm \\
44,864\end{array}$ & $\begin{array}{l}7.84 \pm \\
2.66\end{array}$ \\
\hline Homo sapiens & $\begin{array}{l}24,707,901 \\
10,494,620\end{array}$ & \pm & $\begin{array}{l}20,522 \pm \\
12,709\end{array}$ & $\begin{array}{l}1579.37 \pm \\
817.6\end{array}$ & $\begin{array}{l}145,732 \pm \\
62,153\end{array}$ & $\begin{array}{l}9.44 \pm \\
6.05\end{array}$ \\
\hline
\end{tabular}

\section{Figures}



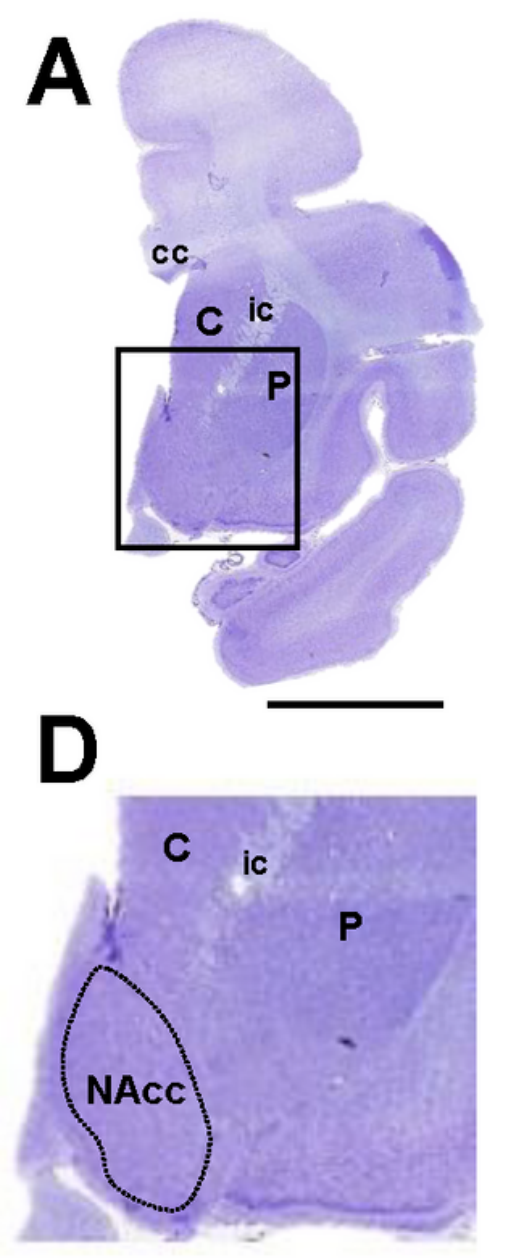
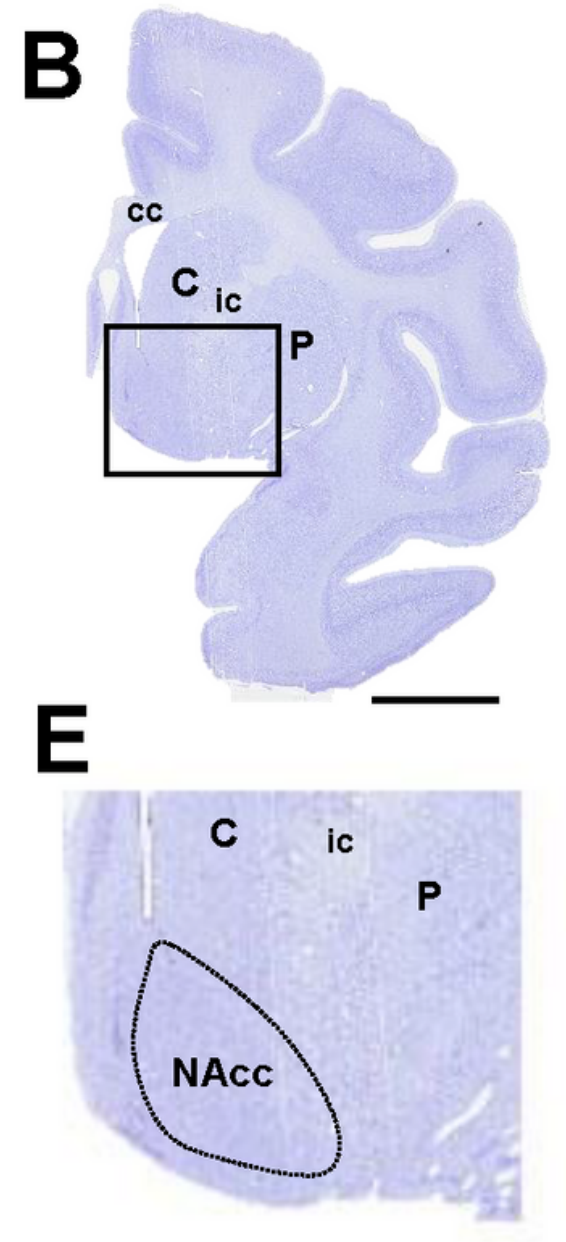
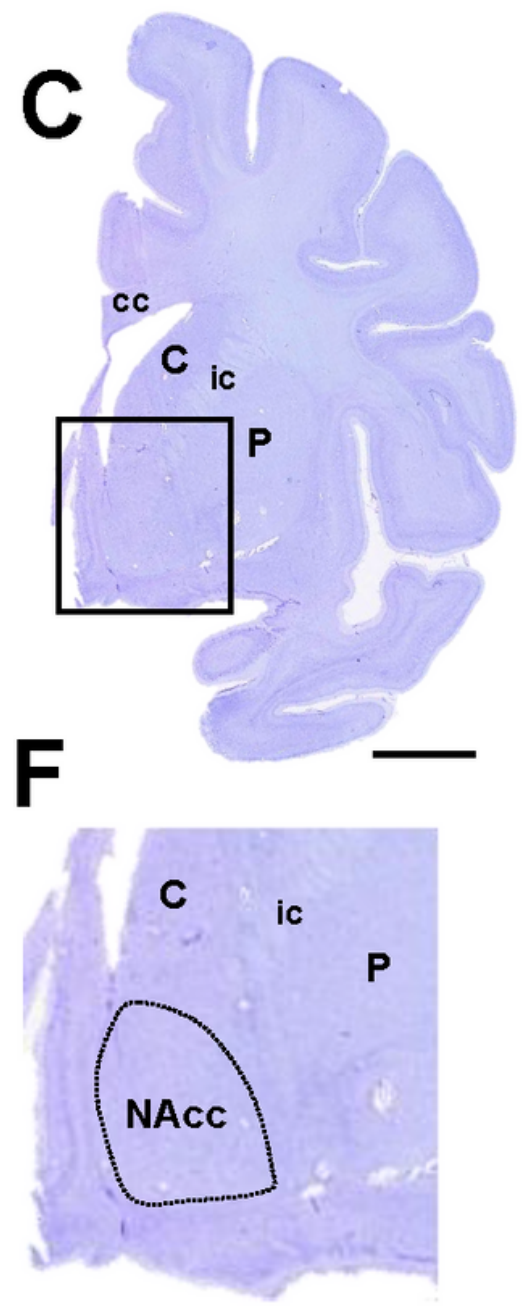

\section{Figure 1}

Nissl-stained coronal sections showing the nucleus accumbens in capuchin $(A, D)$, macaque $(B, E)$, and chimpanzee $(C, F)$. The regions outlined in $A, B$, and $C$ are shown at higher resolution in $D, E$, and $F$, respectively. The NAcc sampled was conservatively estimated to avoid sampling within the ventral striatum, as the border between these regions is indistinct. Abbreviations: ac, anterior commissure; $\mathrm{C}$, caudate nucleus; cc, corpus callosum ; ic, internal capsule; P, putamen, NAcc, nucleus accumbens. Scale bar $=1 \mathrm{~cm}$ for panels $\mathrm{A}, \mathrm{B}$, and $\mathrm{C}$. 

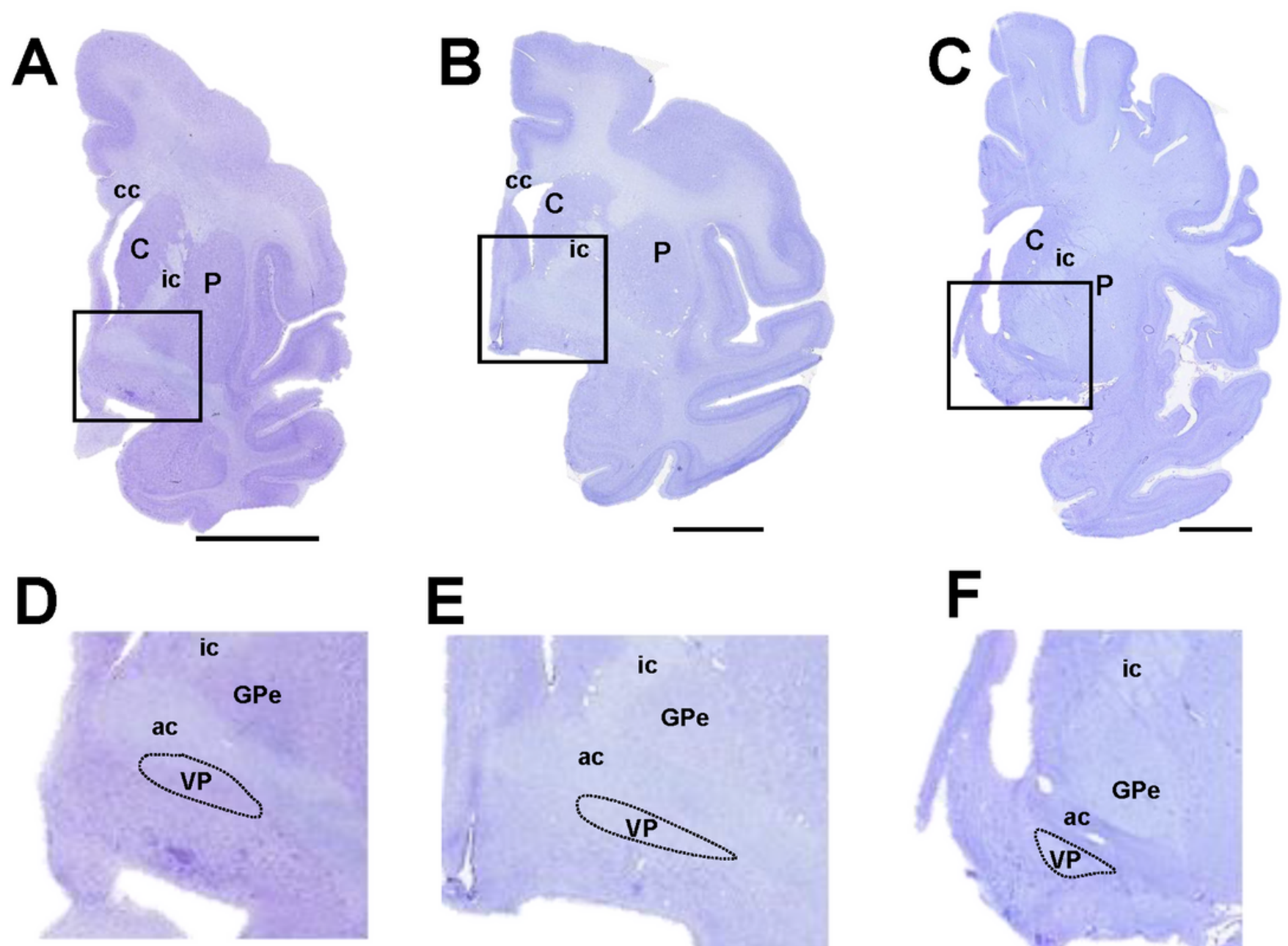
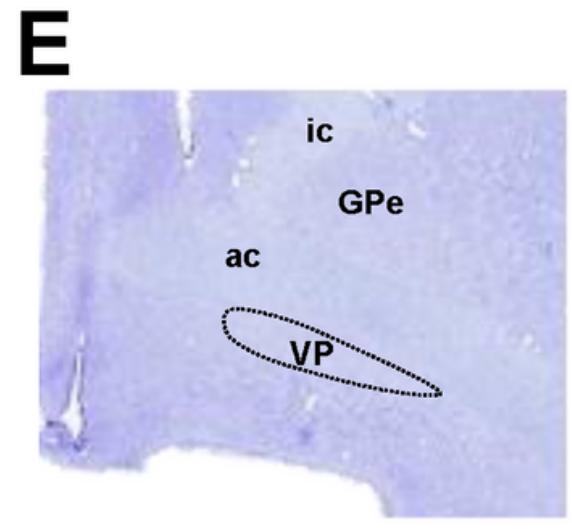

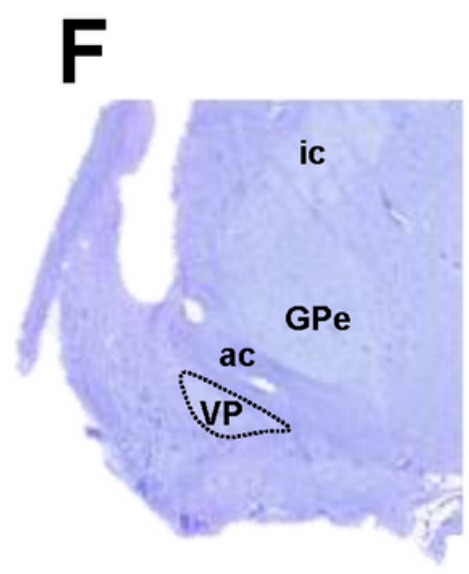

\section{Figure 2}

Nissl-stained coronal sections showing the ventral pallidum (VP) in capuchin $(A, D)$, macaque $(B, E)$, and chimpanzee $(C, F)$. The regions outlined in $A, B$, and $C$ are shown at higher resolution in $D, E$, and $F$, respectively. Abbreviations: ac, anterior commissure; $C$, caudate nucleus; $c c$, corpus callosum ; ic, internal capsule; GPe, external globus pallidus; P, putamen, VP, ventral pallidum. Scale bar $=1 \mathrm{~cm}$ for panels A, B, and $\mathrm{C}$. 

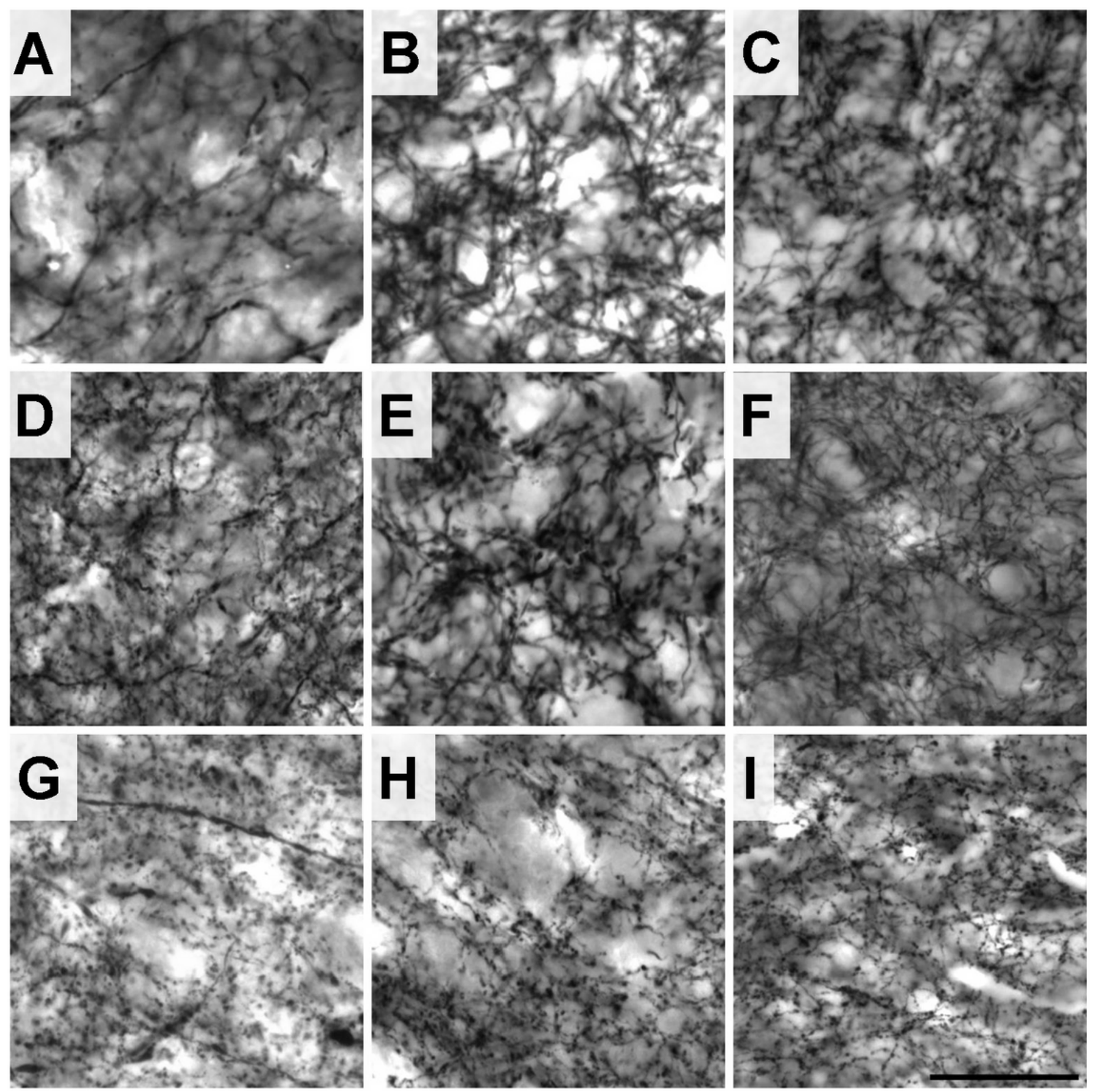

\section{Figure 3}

High-magnification photomicrographs of TH-ir axons in the NAcc in marmoset. (A), tamarin (B), owl monkey $(C)$, capuchin $(D)$, rhesus macaque $(E)$, pig-tailed macaque $(F)$, chimpanzee $(G)$, bonobo $(H)$, and human (I). Scale bar $=25 \mu \mathrm{m}$. 

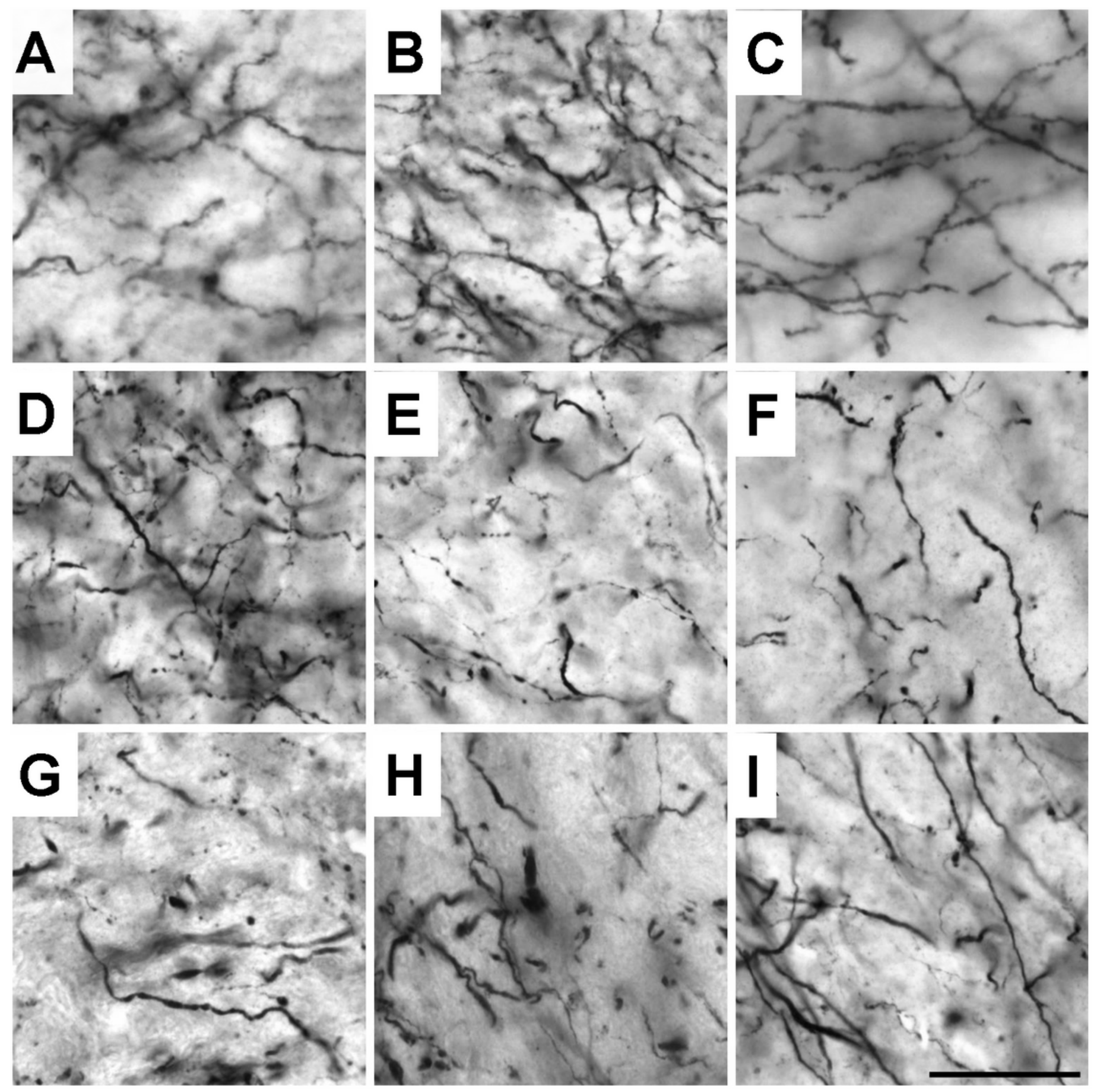

\section{Figure 4}

High-magnification photomicrographs of TH-ir axons in the VP in marmoset (A), tamarin (B), owl monkey $(C)$, capuchin $(D)$, rhesus macaque $(E)$, pig-tailed macaque $(F)$, chimpanzee $(G)$, bonobo $(H)$, and human (I). Scale bar $=25 \mu \mathrm{m}$. 

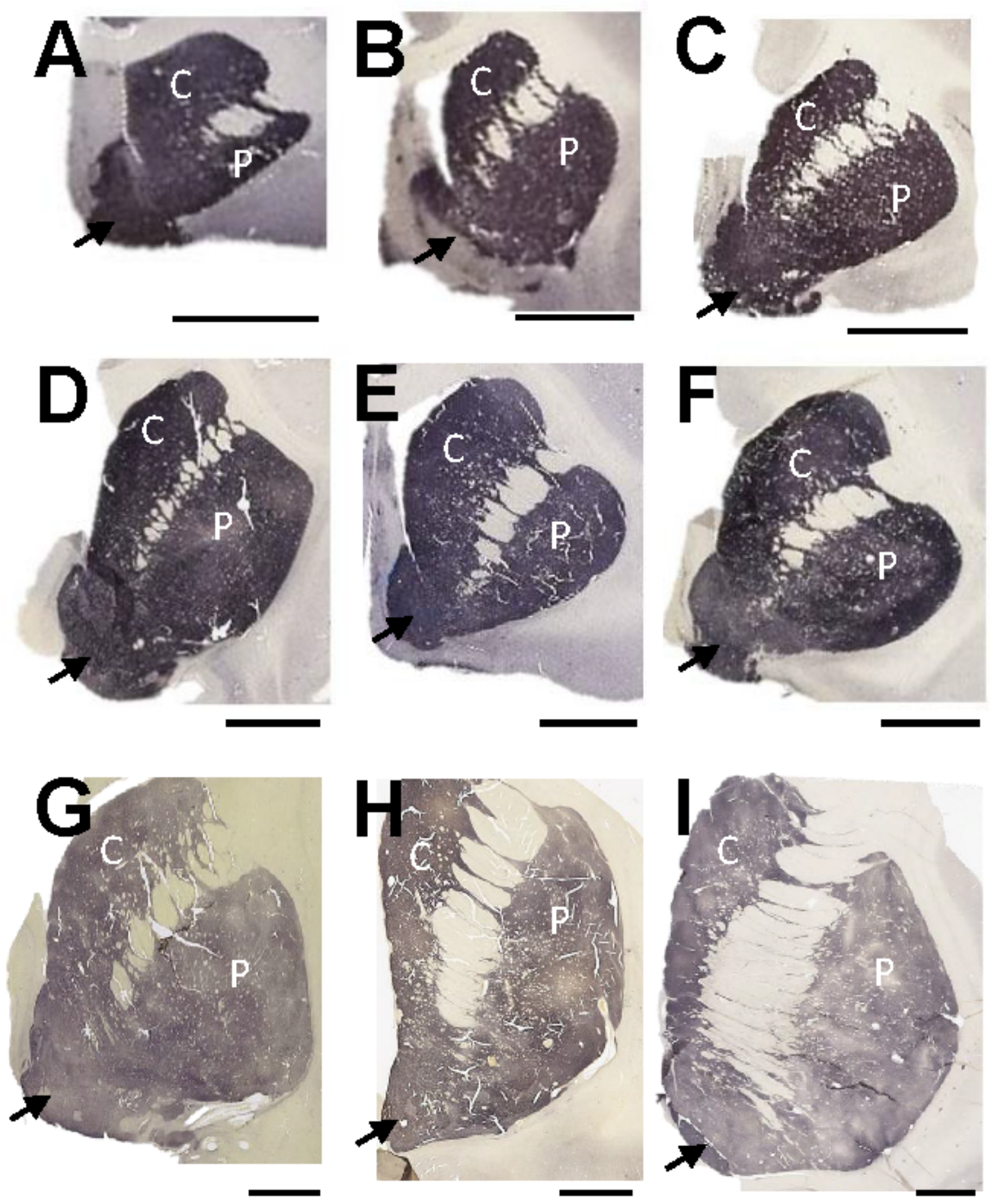

\section{Figure 5}

Low-power photomicrographs showing TH-immunostained sections containing the NAcc. The NAcc is indicated by arrows. Note that there is not an obvious distinction between the shell and core regions of the NAcc. Abbreviations: $\mathrm{C}=$ caudate nucleus, $\mathrm{P}=$ putamen. Scale bars $=0.5 \mathrm{~cm}$. 

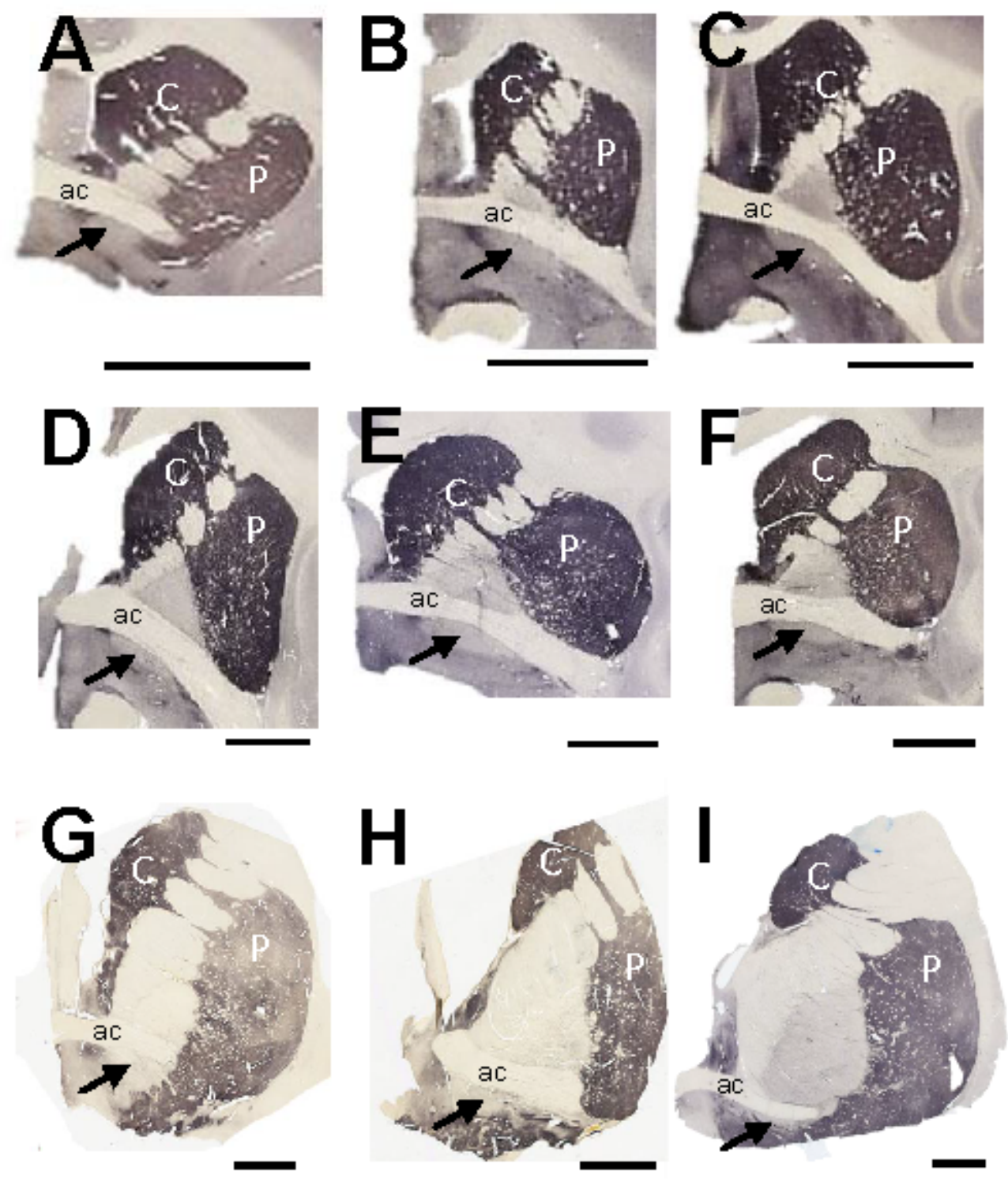

Figure 6

Low-power photomicrographs showing TH-immunostained sections containing the VP. The VP is indicated by arrows and is easily identifiable in all sections with its distinct borders. Abbreviations: $\mathrm{C}=$ caudate nucleus, $\mathrm{P}=$ putamen, $\mathrm{ac}=$ anterior commissure. Scale bars $=0.5 \mathrm{~cm}$ 


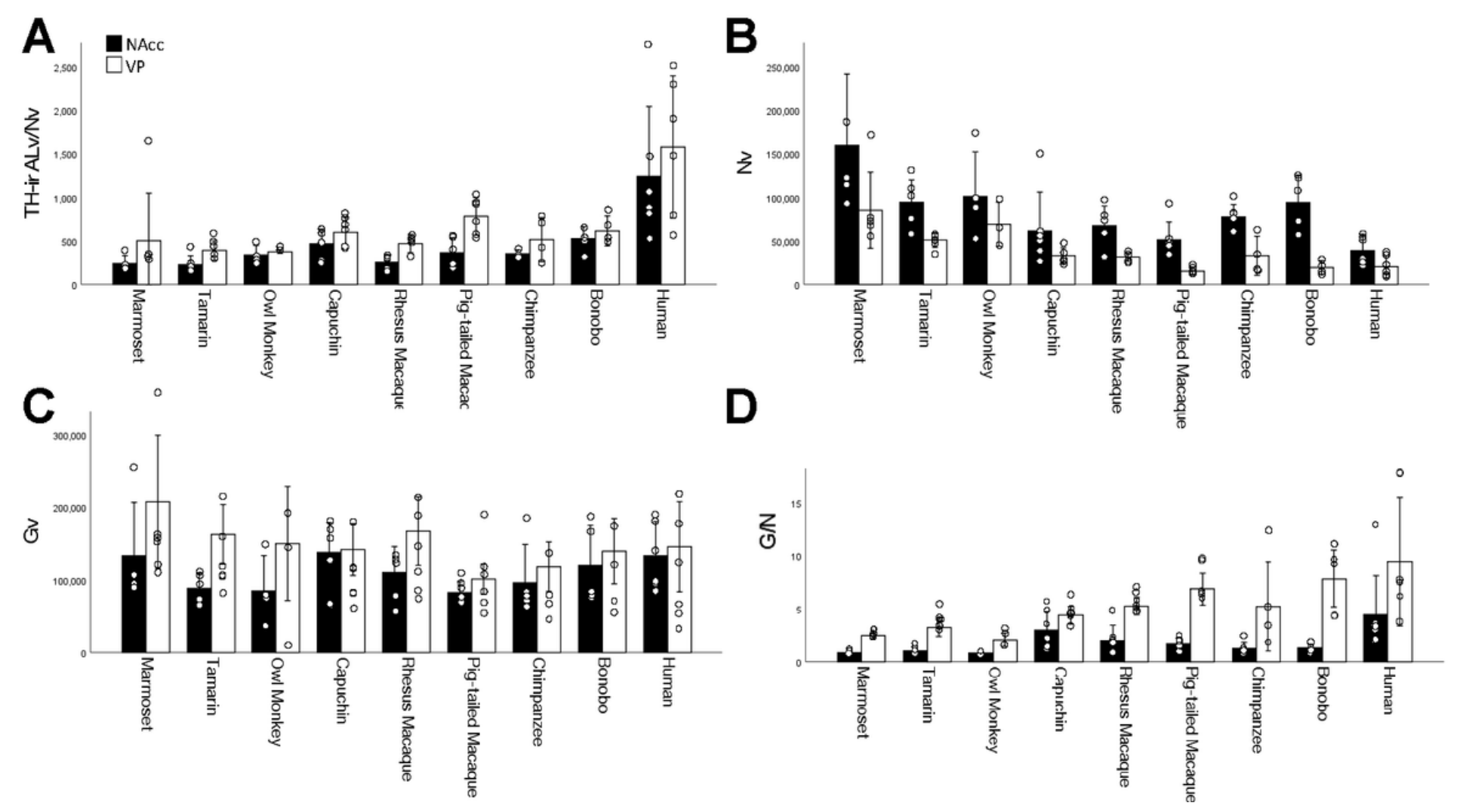

Figure 7

Bar graphs showing mean TH-ir Alv/Nv (A), Nv (B), Gv (C), and G/N ratio (D) in the NAcc and VP by species. The open circles represent individual values. Error bars show +/- 1 SD.
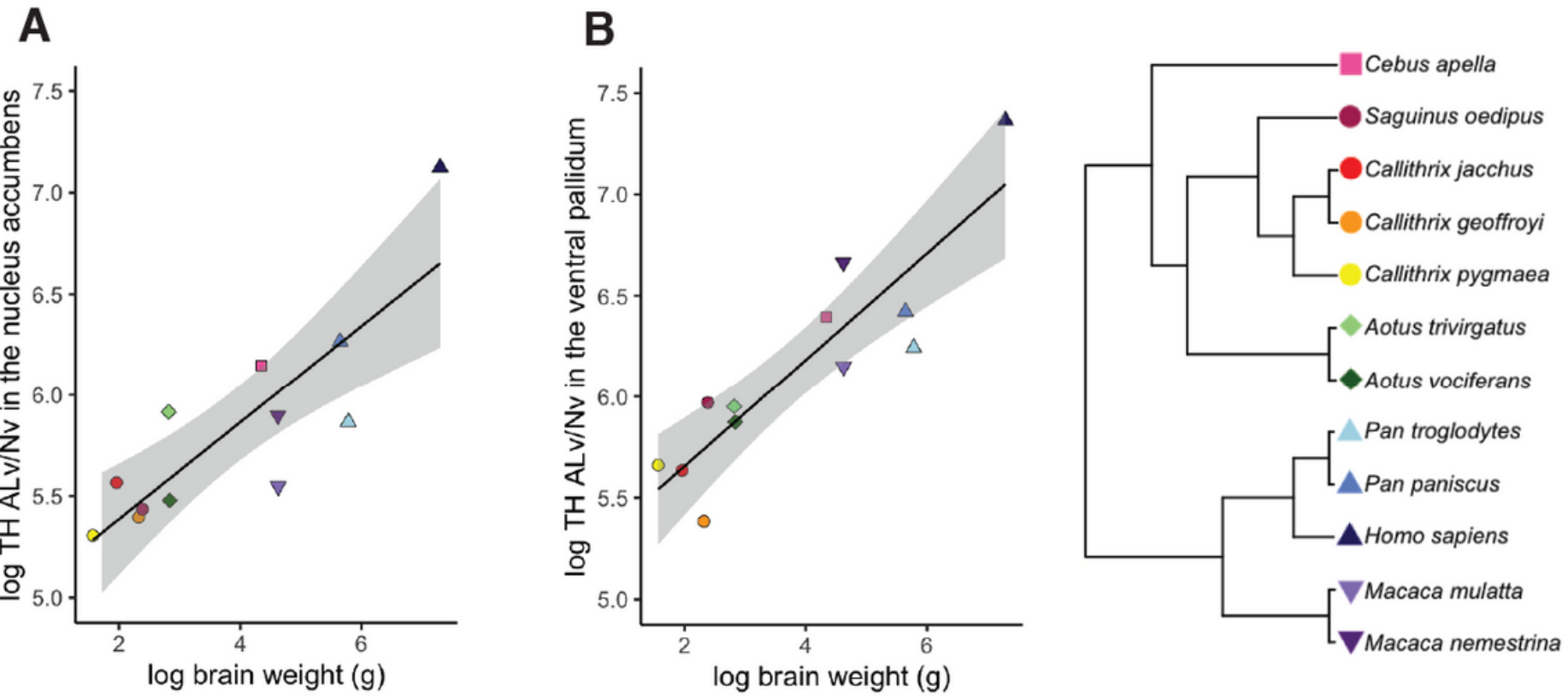

Figure 8 
PGLS regressions of TH AL/Nv against brain weight shown with 95\% confidence intervals for nucleus accumbens (A) and ventral pallidum (B). The phylogenetic tree in this figure provides the color/shape legend for species values in all plots of PGLS analyses.
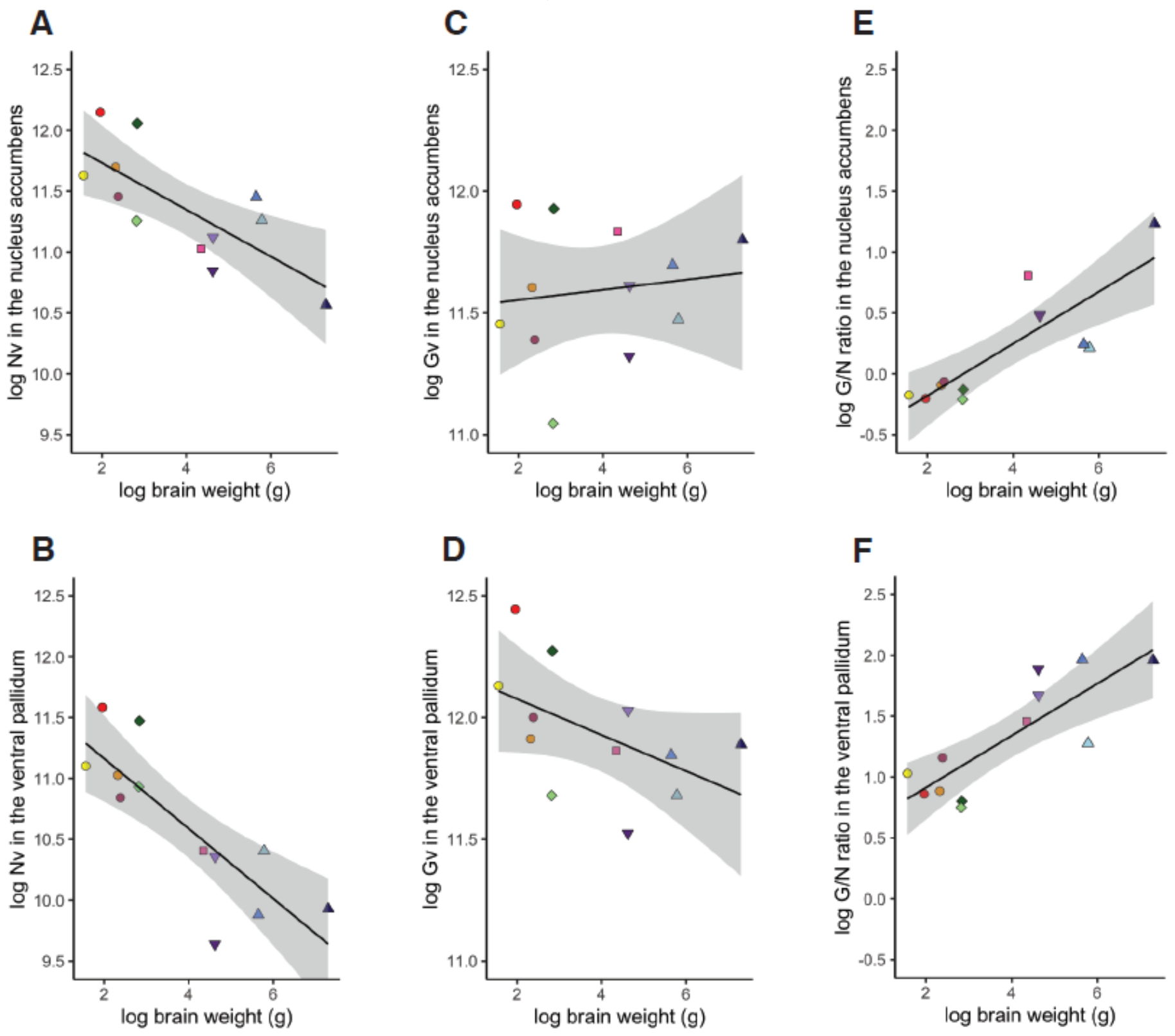

\section{Figure 9}

PGLS regressions against brain weight shown with 95\% confidence intervals for $\mathrm{Nv}$ in the nucleus accumbens (A) and ventral pallidum (B), Gv in the nucleus accumbens (C) and ventral pallidum (D), and $\mathrm{G} / \mathrm{N}$ ratio in the nucleus accumbens $(\mathrm{E})$ and ventral pallidum $(\mathrm{F})$. The phylogenetic tree in this figure provides the color/shape legend for species values in all plots of PGLS analyses. 